\title{
Electrodiagnostic confirmation of long thoracic nerve palsy
}

\author{
PAUL E KAPLAN
}

From the Department of Rehabilitation Medicine, Northwestern University, Chicago, Illinois, USA

SUMMARY Long thoracic nerve latencies were measured in 25 normal subjects. The nerve was stimulated at Erb's point. Monopolar electrodes were used to record the motor evoked response from the serratus anterior muscle. The mean long thoracic nerve latency was $3.9 \pm 0.6 \mathrm{~ms}$. Four athletes with unilateral, isolated long thoracic nerve palsies were compared with the control group and with the uninvolved extremities. Long thoracic nerve latency examinations may help confirm the presence of long thoracic nerve palsy and test proximal nerve conduction.

In the past 20 years, latencies of muscle responses from excitation of nerves to muscles of the shoulder girdle have been studied repeatedly. ${ }^{1-4}$ The axillary, musculocutaneous, and suprascapular nerves have been stimulated proximally at Erb's point or at the axilla, and the latencies recorded have involved travel of the electrical impulse across parts of the brachial plexus. Indeed, at least one study has referred to them as "brachial plexus latencies".

A long thoracic nerve latency would represent a less complicated example of proximal nerve conduction. However, none of the above studies have determined latencies from long thoracic nerve stimulation. Recently, four athletes presented with unilateral, isolated long thoracic nerve palsies and, therefore, presented a need for the electrodiagnostic study of this nerve.

The long thoracic nerve is formed directly from the fifth, sixth, and seventh cervical spinal nerve roots. ${ }^{6}$ As a result, it is not a part of the brachial plexus but passes posterior to it and upon the anterior surface of the scalenus medius (fig 1). The nerve is $15-20 \mathrm{~mm}$ behind the clavicle and angulates over the first or second ribs following the thoracic wall. It is attached at its end to the serratus anterior which it innervates. During its course down the neck and thoracic wall, traction will be exerted upon the nerve with

Address for reprint requests: Dr Paul E Kaplan, Rehabilitation Institute of Chicago, 345 East Superior Street, Chicago, Illinois 60611, USA.

Accepted 7 June 1979 shoulder depression or with contralateral bending movements of the cervical spine.

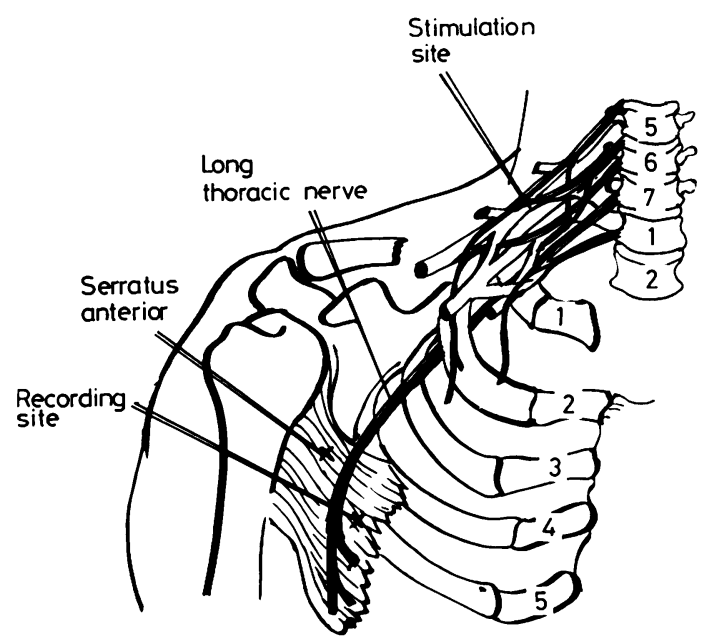

Fig 1. Anatomical course of the long thoracic nerve.

\section{Method}

Twenty-five healthy male and female unpaid volunteers (control group) were studied. None of the subjects had any evidence of peripheral neuropathy, diabetes, renal disease, shoulder girdle atrophy, or any other abnormalities. The age range was 19-55 years, and the median was 33 years.

Four male athletes (neuropathy group) were 
studied. Two were football players, and two basketball players. None had any past history of peripheral neuropathy, diabetes, renal disease, or shoulder girdle atrophy before the onset of the injury. All were injured during the course of a game. The age range was 18-22 years, and the median was 19 years. All were evaluated five to seven weeks after the injury.

The temperature of the room in which the examinations were performed was $21-23^{\circ} \mathrm{C}$. A TECA TE-4 electromyograph was used for all studies with a storage oscilloscope. The latency values were measured to the first deflection from the isoelectric line of the evoked potential. Infrared direct rewriting equipment as well as Polaroid photographs were used to record the evoked potentials.

The long thoracic nerve was stimulated at Erb's point (above the upper margin of the clavicle lateral to the clavicular head of the sternocleidomastoid muscle). The cathode of the surface stimulation electrode was placed at Erb's point, and the anode was located above and medially. The earth (ground) electrode was placed upon the thoracic wall at the anterior axillary line at the T2 rib level. A monopolar electrode was placed into the digitation of the serratus anterior at the T5 rib level at the midaxillary line. The position of the electrode was verified by having the subject attempt protraction of the shoulder. The inactive surface electrode was placed $20 \mathrm{~mm}$ caudally to the active electrode. Distances were measured with obstetric calipers. This method has given more reliable measurements than did tape measurements. ${ }^{7}$ All four subjects in the neuropathy group had electromyographic examination of the involved extremity.

\section{Results}

All the athletes initially had dull shoulder aches and weakness on abduction and protraction of the shoulder. With the shoulder abducted, pushing forward against a wall revealed winging of the scapula.

All values are expressed as mean \pm standard deviation. All values differing from control ( $t$ test) at a $1 \%$ significance level are marked with an asterisk.

The range of distance for both groups from the point of stimulation to the point of recording was $170-230 \mathrm{~mm}$. The mean latency in the control goup was $3.9 \pm 0.6 \mathrm{~ms}$. That of the uninvolved extremity of the neuropathy group was $3.8 \pm 0.5 \mathrm{~ms}$. The latency for the involved extremity of the neuropa thy group was $6 \cdot 3 \pm 0 \cdot 3 \mathrm{~ms}^{*}$ (figs 2,3 ).
All the athletes showed fibrillations and sharp waves in the involved serratus anterior. On attempted voluntary contraction, a decreased number of motor unit action potentials were recruited. The motor unit potentials that were recruited fired at a more rapid rate than expected for the strength of the contraction. In all the athletes, the deltoid, biceps, triceps, infraspinatus, latissimus dorsi, abductor pollicis brevis, and erector spinae muscles were normal.

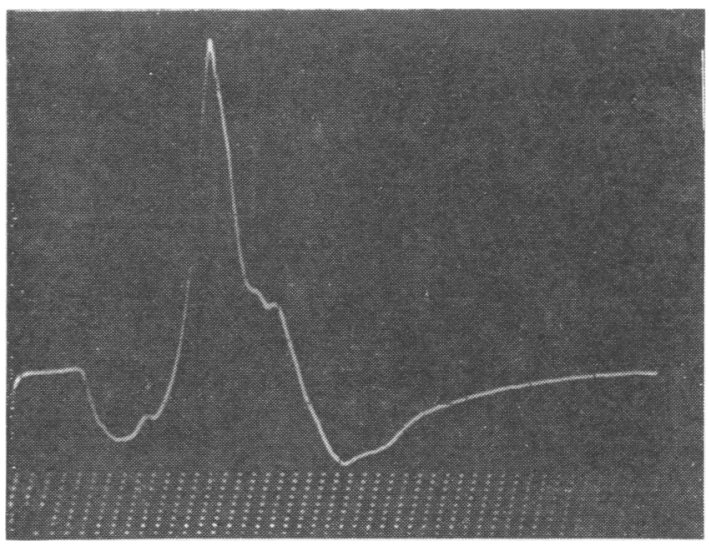

Fig 2. Motor evoked potential after stimulation of a normal long thoracic nerve. The height of the time line is $1 \mathrm{mV}$. Each dot is $0.1 \mathrm{~ms}$.

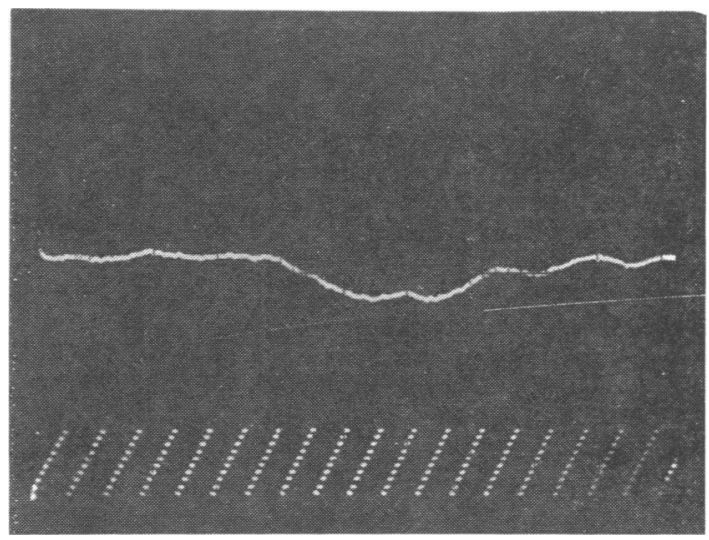

Fig 3. Motor evoked potential after stimulation of the involved long thoracic nerve from the neuropathy group. The height of the time line is $1 \mathrm{mV}$. Each dot is $0 \cdot 1 \mathrm{~ms}$.

All four athletes recovered from their injuries within a year of examination. The mean response latency of the neuropathy group after recovery was $4 \cdot 0 \pm 0.5 \mathrm{~ms}$. 


\section{Discussion}

It has been shown that either surface or deeply placed concentric recording electrodes are probably preferable to monopolar recording electrodes. This situation is especially true with regard to the amplitude of the evoked potential and to the sharpness of the deviation from the isoelectric baseline. ${ }^{8}$ However, the stimulation of the long thoracic nerve at Erb's point was not limited to that nerve. Therefore, a major disadvantage of stimulation at Erb's point lies in the inadvertent recording of a volume conducted potential from the latissimus dorsi. This situation is particularly true for patients with long thoracic nerve palsy. Recording percutaneously from the serratus anterior is a way of meeting that objection. On the other hand, the comfort, safety, and convenience of monopolar electrodes were important advantages when compared to the use of concentric electrodes. Use of a hollow electrode might result in production of tension pneumothorax.

Long thoracic nerve palsy has been produced by downward strains on the shoulders caused by well-loaded knapsacks. ${ }^{9}$ It has also been noted after strenuous exertion ${ }^{10}$ and in patients with brachial plexus neuritis. ${ }^{11}$ Indeed, downward shoulder traction and lateral flexion of the neck may also lead to neuropathy of the upper trunk of the brachial plexus ${ }^{4}$ as well as palsy of the long thoracic nerve.

However, even though the mechanisms of injury are similar, the brachial plexus and long thoracic nerve injuries may be separate and distinct. Prescott and Zollinger ${ }^{12}$ reported that abduction of the shoulder beyond $90^{\circ}$ might lead to an isolated palsy of the long thoracic nerve and that excellent recovery from this lesion could be observed. This last situation is probably related to the long thoracic nerve palsies noted in the four athletes. Both basketball and football may, on occasion, require sudden and forceful abduction of the shoulder beyond $90^{\circ}$. All four of the injured athletes recovered completely. Goodman et $a l^{13}$ have reported traumatic long thoracic nerve palsy with only partial or no recovery. Our patients were more like those reported by Prescott and Zollinger. ${ }^{12}$

Whether long thoracic nerve palsy is isolated or is accompanied by neuropathy of the upper trunk of the brachial plexus, determination of the long thoracic nerve latency will help confirm a palsy of this nerve. The long thoracic nerve latency may also be a method for evaluating proximal nerve conduction in systemic diseases.

\section{References}

1 Redford JWB. Conduction time in motor fibers of nerves which innervate proximal muscles of extremities in normal persons and patients with neuromuscular diseases. Thesis, University of Minnesota, 1958.

2 Gassel MM. Test of nerve conduction to muscles of shoulder girdle as aid in diagnosis of proximal neurogenic and muscular disease. J Neurol Neurosurg Psychiatry 1964; 27: 200-5.

3 Vacek J, Drugova B. Proximalni amyotrofie: elektromyograficka stimulace erbova boda. Cesk Neurol Newochir 1967; 30:183-90.

4 Kraft G. Axillary, musculocutaneous, and suprascapular nerve latency studies. Arch Phys Med Rehabil 1972; 52:383-7.

5 Chokroverty S, Medina J. Electrophysiological study of hemiplegia. Arch Neurol 1978; 35: 360-3.

6 Horwitz MT, Tocantins LM. An anatomical study of the role of the long thoracic nerve and the related scapular bursae in the pathogenesis of local paralysis of the serratus anterior muscle. Anat Rec 1938; 71:375-85.

7 Gassel MM, Diamantopoulos E. Pattern of conduction times in the distribution of the radial nerve. A clinical and electrophysiological study. Neurology (Minneap) 1964; 14:222-31.

8 Horning MR, Kraft GH, Guy A. Latencies recorded by intramuscular needle electrodes in different portions of a muscle: variations and comparison with surface electrodes. Arch Phys Med Rehabil 1972; 53:206-11.

9 Ilfeld EW, Holder HG. Winged scapula. Case occurring in soldier from knapsack. JAMA 1942; 120:448-9.

10 Overpeck DO, Ghomley RK. Paralysis of the serratus magnus muscle caused by lesions of the long thoracic nerve. JAMA 1940; 114: 1994-6.

11 Tsairis P, Dyck PJ, Mulder DW. Natural history of brachial plexus neuropathy. Arch Neurol 1972; 27:109-17.

12 Prescott MU, Zollinger RW. Alar scapula. An unusual surgical complication. Am J Surg 1944; 65:98-103.

13 Goodman CE, Kenrick MM, Blum MV. Long thoracic nerve palsy: a follow-up study. Arch Phys Med Rehabil 1975; 56:352-5. 